\title{
Computer Vision Syndrome among Patients Attending the Outpatient Department of Ophthalmology in a Tertiary Care Centre: A Descriptive Cross-sectional Study
}

\author{
Priyanka Shrestha, ${ }^{1}$ Pranil Man Singh Pradhan, ${ }^{2}$ Om Krishna Malla ${ }^{1}$ \\ 'Department of Ophthalmology, Kathmandu Medical College Teaching Hospital, Kathmandu, Nepal, ${ }^{2}$ Department of \\ Community Medicine, Institute of Medicine, Tribhuvan University, Kathmandu, Nepal.
}

\section{ABSTRACT}

Introduction: Computers and digital electronic devices have become an integral part of life. These devices have adverse effects and nowadays are considered leading occupational hazards. Computer vision syndrome comprises of all the ocular, visual and musculoskeletal symptoms secondary to long term computer use. The objective of this study is to determine the prevalence of computer vision syndrome among people attending the outpatient department of ophthalmology in the tertiary care center in Nepal.

Methods: A descriptive cross-sectional study was done among 70 patients in a tertiary care hospital from January 2017 to June 2017 after obtaining ethical approval from the institutional review committee (Ref: 12042017). Convenient sampling method was applied and the point estimate at 95 $\%$ confidence interval was calculated along with frequency and proportion for binary data. Patients using computers for more than one hour were included in the study. All data were entered in Microsoft Excel and analyzed using statistical package for social sciences version 20.

Results: Among 70 patients, 67 (95.7\%) (87.9-99.1 at 95\% confidence interval) had one or more symptoms on computer use. The mean duration of computer use was $7.5 \pm 5.4$ years and average hours of computer use among computer users were $6.9 \pm 3$ hours. The most common symptom among computer users was headache seen in $46(62.2 \%)$ patients.

Conclusions: Our study showed that a significant number of people using a computer develop one or more symptoms on the long-term use of the computer. Therefore, it is very important to create awareness regarding computer vision syndrome and methods to prevent it among computer users.

Keywords: computer; vision syndrome; ergonomics.

\section{INTRODUCTION}

Computers and digital electronic devices are being largely used nowadays not only in the form of the desktop at the workplace but also in the form of laptops, tablets, and smartphones. Both adults and children use it for email, entertainment, communication, work, gaming, etc. ${ }^{1}$ Their use are not without adverse effects. Computer Vision Syndrome (CVS) is a rapidly growing problem among Video Display Terminal (VDT) users among both professional and ordinary computer users.

American Optometric Association in 1995 defined CVS as "the complex of eye and vision problems related to near work which are experienced during or related to computer use."'2 The ocular complaints include eye strain, eye fatigue, irritation, redness, dry eyes, blurred vision, and burning sensation and non-ocular symptoms

Correspondence: Dr. Priyanka Shrestha, Department of Ophthalmology, Kathmandu Medical College Teaching Hospital, Kathmandu, Nepal. Email: priyankashresthapradhan@gmail.com, Phone: +977-9851074622. 
Shrestha et al. Computer Vision Syndrome among Patients Attending the Outpatient Department of Ophthalmology..

include headaches, shoulder, neck and back pain. ${ }^{3}$

Therefore, the objective of this study is to determine the prevalence of computer vision syndrome among people attending the outpatient department of ophthalmology in the tertiary care center in Nepal.

\section{METHODS}

A descriptive cross-sectional study was done among 70 patients in Kathmandu Medical College from January 2017 to June 2017 after obtaining ethical approval from the institutional review committee of Kathmandu Medical College Teaching Hospital (Ref: 12042017). The convenient sampling method was applied. The inclusion criteria were patients aged 18 to 39 years who visited the Ophthalmology outpatient department of Kathmandu Medical College Teaching Hospital. The patients who did not give consent were excluded from the study.

Sample size calculation,

$\mathrm{n}=\mathrm{Z}^{2} \times \mathrm{p} \times(1-\mathrm{p}) / \mathrm{e}^{2}$

$=(1.96)^{2} \times 0.79 \times 0.21 /(0.1)^{2}$

$=0.64 / 0.01$

$=64$

Where,

$\mathrm{n}=$ sample size

$Z=1.96$ at $95 \%$ confidence interval $(\mathrm{Cl})$

$\mathrm{p}=$ prevalence, $79 \%{ }^{4}$

$\mathrm{e}=$ margin of error, $10 \%$

Therefore, the sample size calculated was 64. Taking a non-response rate of $10 \%$, the total sample size was 70 .

All subjects were requested to fill a written questionnaire regarding their computer use and symptoms observed during computer use. The questionnaire included age, sex, average working hours a day, type of work, total time (in months/years) of work on the computer, history of eye problems and/or consultation with an eye doctor, use of computer eyeglasses, refractive correction (glasses), use of an antiglare screen, brightness adjustment, windows position, idea of CVS, symptoms experienced, non-ocular problems (muscle pain) and relief measures. A complete ophthalmological examination was done which included best-corrected visual acuity, refractive error, anterior and posterior segment evaluation, dry eye evaluation, convergence, accommodation, and fundus examination. The questionnaire, used in similar previous studies, was tailored for our study. ${ }^{5}$

All data were entered in Microsoft Excel and analyzed using Statistical Package for Social Sciences (SPSS) Version 20. Point estimate at $95 \%$ confidence interval was calculated. Descriptive statistics, frequency tables and percentages were used.

\section{RESULTS}

A total of 70 computer users were enrolled in the study. Among the computer user, 67 (95.7\%) (87.9-99.1 at $95 \%$ confidence interval) had one or more symptoms on computer use. The mean age was 25.64 \pm 5.6 years. Among them 41 (58.6\%) were male and 29 $(41.4 \%)$ were female. Most of the study participants $43(60.8 \%)$ were within the age group 20-29 years. Refractive error was seen in $36(51.4 \%)$ among which $20(28.6 \%)$ were diagnosed with refractive error for the first time (Table 1).

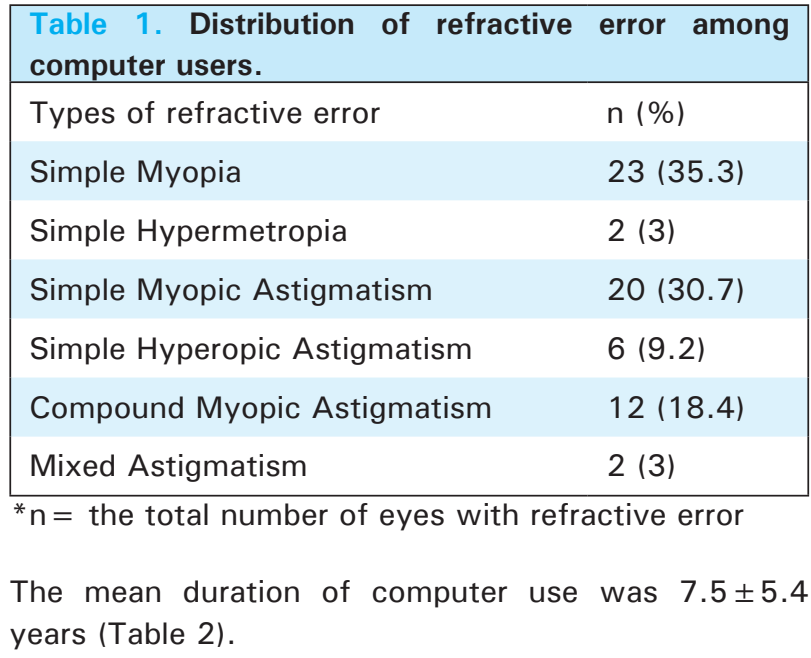

\begin{tabular}{|lc|}
\hline Table 2. Distribution of duration of computer use. \\
\hline Duration ( in years) & $\mathrm{n}(\%)$ \\
$1-5$ & $30(42.8)$ \\
$6-10$ & $25(35.7)$ \\
$11-15$ & $8(11.4)$ \\
$16-20$ & $5(7.1)$ \\
$21-25$ & $2(2.8)$ \\
\hline
\end{tabular}

The average hours of computer use among computer users were $6.9 \pm 3$ hours (Table 3 ).

\begin{tabular}{|ll|}
\hline $\begin{array}{l}\text { Table 3. Distribution of hours of use of computers } \\
\text { among computer users. }\end{array}$ \\
\hline Hours of computer use & $\mathrm{n}(\%)$ \\
$1-5$ & $22(31.4 \%)$ \\
$6-10$ & $43(61.4 \%)$ \\
$11-15$ & $4(5.7 \%)$ \\
$16-20$ & $1(1.4 \%)$ \\
\hline
\end{tabular}

Among the computer users, 40 (57.1\%) used laptops only 9 (12.9\%) used desktop only and 21 (28.4\%) used both laptops and desktops. Most participants used electronic devices for internet use 52 (74.3\%) followed by emails and programming in $43(61.4 \%)$ and 23 
(32.9\%) respectively. The mean duration of computer use after which the subjects developed symptoms was 3.2 hours. The most common symptom among computer users was headache seen in $46(62.2 \%)$ (Table 4).

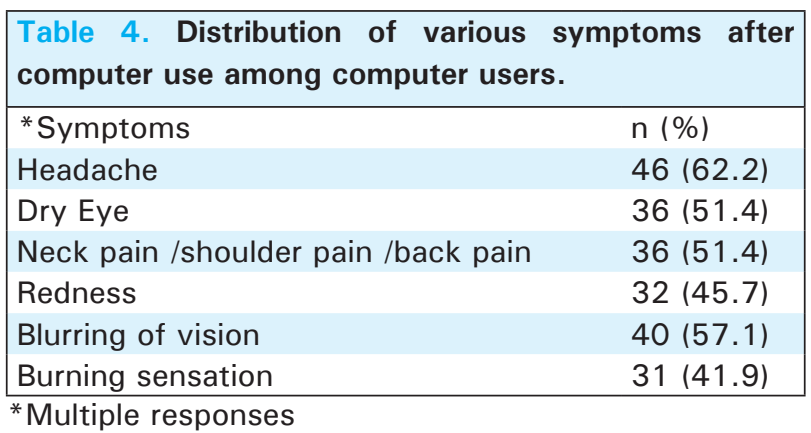

The most common preventive measures taken by the computer user was taking frequent breaks in 57 (64\%) (Table 5).

\begin{tabular}{|c|c|}
\hline \multicolumn{2}{|c|}{$\begin{array}{l}\text { Table } 5 \text {. Distribution of various preventive measures } \\
\text { taken by computer users. }\end{array}$} \\
\hline *Preventive measures & $\mathrm{n}(\%)$ \\
\hline Taking frequent breaks & $57(64)$ \\
\hline Use of eye drops & $14(15.7)$ \\
\hline Use of screen filters & $5(5.6)$ \\
\hline Looking at far objects & $3(14.6)$ \\
\hline No measures are taken & $6(6.3)$ \\
\hline
\end{tabular}

\section{${ }^{*}$ Multiple responses}

Among the computer users, the Schirmers test done after the application of topical anesthesia showed a dry eye in 18 (25.7\%). Tear film break-up time done in all patients showed values less than 10 in 23 (32.9\%). Convergence insufficiency was found in $6(8.6 \%)$ of subjects with computer vision syndrome which was treated accordingly. Among the computer users, 17 (24.3\%) placed the computer screen at a distance of 20-25 inches and $19(27.1 \%)$ had their screen slightly below the eye level.

\section{DISCUSSION}

Computer and visual display terminal have now been a part of our lives. It is said to be the leading cause of occupational hazards of the $21^{\text {st }}$ century. ${ }^{6}$ Among the 70 computer users, $95.7 \%$ had one or more symptoms following the use of a computer continuously for more than one hour. Various studies have shown the prevalence of computer vision syndrome ranging from $46.3 \%-89.9 \%$ among the various group of subjects

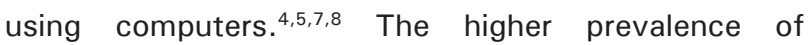
computer vision syndrome in our study could be due to the inclusion of back, neck, and shoulder pain in the diagnosis of computer vision syndrome, and also we have not taken any specific duration of symptoms for the diagnosis of computer vision syndrome.

The mean age of presentation of our participants was 25. Sixty-four patients between 20 to 30 years of age, the observation of which was on par with the mean age presented in other studies done among different groups of participants. ${ }^{9-11}$ The most common symptom among computer users was headache $(62.2 \%)$ followed by dry eye and neck, shoulder $(51.4 \%)$, and back pain $(51.4 \%)$. Headache is a common symptom among computer users in various studies the prevalence ranging from $43 \%-82.1 \% .4$

Working at a computer screen requires greater visual effect than reading a paper which is due to a lesser blink rate, about 7 blinks per minute as compared to a normal blink rate of 22 per minute. ${ }^{6}$ Therefore, longer screen time leads to dry eye and discomfort on computer use. Schirmer's test showed a dry eye in $25.7 \%$ and lower tear film break-up time in $32.9 \%$ which may indicate that evaporative dry eye is more common in subjects with computer vision syndrome. Lower tear film break up time in long term computer users was statistically significant than in control in a study done by Akkaya et al. ${ }^{12}$ Among the computer users $75.7 \%$ were aware of the adverse effects of long term computer use and $64 \%$ among them had been taking frequent breaks while using the computer the results of are similar to a study by Akinbinu et al. ${ }^{13}$

Refractive error was seen in $51.4 \%$ of the computer users and spherical error was present in $38.3 \%$ and astigmatism was present in $61.3 \%$ the results of which did not match with a study done in Nigeria which studied the refractive error among computer users, showed more of spherical error than astigmatic error among the computer users. ${ }^{14}$ Among the subjects with refractive error, $28.6 \%$ had not been corrected for their error which could be a reason for their symptoms while using computers. Since our subjects had more of an astigmatic error and many of them were not corrected for their refractive error, could be one reason a large number of them experiencing symptoms during computer use and a major proportion of them experiencing asthenopic symptoms most commonly headache.

Various ergonomic recommendations have been made to prevent computer vision syndrome which recommends at least a one-arm distance between the computer screen and eye (20-25 inches), the position of the gaze of an eye to the screen being slightly downward, and the use of antiglare screen filters. ${ }^{15}$ However only 
$24.3 \%$ placed the computer screen at a recommended distance, $27.1 \%$ had their screen placed slightly below the eye level and only $5.6 \%$ used anti-glare screen filters. This shows that the subjects in our study did not follow the recommended ocular ergonomics which could be a cause of a higher number of them suffering from computer vision syndrome.

The limitations of our study were small sample size and since the design of the study was a cross-sectional study causal attribution could not be made. Therefore, generalization to the population cannot be done.

\section{CONCLUSIONS}

The prevalence of computer vision syndrome among computer users in our study was $95.7 \%$. Refractive error was seen in $51.4 \%$ and the most common symptom was a headache. The presence of a higher rate of refractive error with many being diagnosed for the first

\section{REFERENCES}

1. Rosenfield M. Computer vision syndrome: a review of ocular causes and potential treatments. Ophthalmic Physiol Opt. 2011;31(5):502-15. [PubMed | Full Text | DOI]

2. American Optometric Association. The Effects of Computer Use on Eye Health and Vision. Am Optom Assoc [Internet]. 1997;(314):1-9. Available from: https://www.aoa.org/ Documents/optometrists/effects-of-computer-use.pdf. [Full Text]

3. Blehm C, Vishnu S, Khattak A, Mitra S, Yee RW. Computer vision syndrome: a review. Surv Ophthalmol. 2005;50(3):253-62. [PubMed | Full Text | DOI]

4. Logaraj M, Madhupriya V, Hegde S. Computer vision syndrome and associated factors among medical and engineering students in Chennai. Ann Med Health Sci Res. 2014;4(2):179-85. [PubMed | Full Text | DOI]

5. Reddy SC, Low CK, Lim YP, Low LL, Mardina F, Nursaleha MP. Computer vision syndrome: a study of knowledge and practices in university students. Nepal J Ophthalmol. 2013;5(2):161-8. [Full Text | DOI]

6. Namrata Arora Charpe \& Vandana Kaushik (2009) Computer Vision Syndrome (CVS): Recognition and Control in Software Professionals, Journal of Human Ecology, 28:1, 67-9. [Full $\underline{\text { Text }}$ | DOI]

7. Assefa NL, Weldemichael DZ, Alemu HW, Anbesse DH. Prevalence and associated factors of computer vision syndrome among bank workers in Gondar City, northwest time, the inclusion of musculoskeletal symptoms for the diagnosis of computer vision syndrome, and poor adherence to computer ergonomics could be associated with a higher rate of computer vision syndrome in our study.

\section{ACKNOWLEDGEMENTS}

Our sincere thanks and appreciation to all the participants of the study who provided their valuable time in this study. We acknowledge the Department of Ophthalmology, Kathmandu Medical College Teaching Hospital for their support. We acknowledge Dr. Gunjan Prasai, Dr. Ashesh Rai, Optometrists Samip Adhikari, and Sagun Shrestha for their support during the entire period of the study.

\section{Conflict of Interest: None.}

Ethiopia, 2015. Clin Optom (Auckl). 2017;9:67-76. [PubMed | Full Text | DOI]

8. Bhanderi DJ, Choudhary S, Doshi VG. A community-based study of asthenopia in computer operators. Indian J Ophthalmol. 2008;56(1):51-5. [PubMed | Full Text | DOI]

9. Venkatesh SH, Girish AT, Kulkarni P, Mannava S. A Study of Computer Vision Syndrome at the Workplace Prevalence and Causative Factors. Int J Contemp Med Res. 2016;3(8):2375-7. [Full Text]

10. Hassan HMJ, Ehsan S, Arshad HS. Frequency of Computer Vision Syndrome \& Ergonomic Practices among Computer Engineering Students. Int J Sci Res. 2016;5(5):121-5. [피l Text]

11. Shrestha GS, Mohamed FN, Shaha DN. Visual problems among video display terminal (VDT) users in Nepal. J Optom. 2011;4(2):56-62. [․ㅏll Text]

12. Akkaya S, Atakan T, Acikalin B, Aksoy S, Ozkurt Y. Effects of long-term computer use on eye dryness. North Clin Istanb. 2018;5(4):319-22. [uued | Full Text | DOI]

13. Akinbinu YJM. Knowledge of computer vision syndrome among computer users in the workplace in Abuja, Nigeria. J Physiol Pathophysiol. 2013;4(4):58-63. [Full Text | DOI]

14. Onyekonwu G. Pattern Of Refractive Errors Among Computer Users In A Nigerian Urban Community. Ebonyi Med J. 2007;6(2):83-8. [Full Text | DOI]

15. Turgut B. Ocular Ergonomics for the Computer Vision Syndrome. Journal of Eye and Vision. 2018;1:1-2. [Full Text]

The Author(s) 2018

This work is licensed under a Creative Commons Attribution 4.0 International License. The images or other third party material in this article are included in the article's Creative Commons license, unless indicated otherwise in the credit line; if the material is not included under the Creative Commons license, users will need to obtain permission from the license holder to reproduce the material. To view a copy of this license, visit http://creativecommons.org/licenses/by/4.0/ 